\title{
Penatalaksanaan fraktur mandibula pada anak menggunakan teknik circumferential wiring dengan Gunning splint Management of mandibular fracture in children using circumferential technique with Gunning splint
}

\author{
${ }^{1}$ S. Haryoseno, ${ }^{2}$ Abel Tasman Yuza, ${ }^{3}$ Bambang A. Sulthana \\ ${ }^{1}$ Program Pendidikan Dokter Gigi Spesialis Bedah Mulut \\ ${ }^{2}$ Bagian Bedah Mulut Fakultas Kedokteran Gigi \\ ${ }^{3}$ Bagian Bedah Fakultas Kedokteran Umum \\ Universitas Padjajaran/Perjan RS. Dr. Hasan Sadikin \\ Bandung, Indonesia
}

\begin{abstract}
Fractures of the mandible in children most commonly occur in the condyle and angulus. Circumferential wiring and Gunning splint as a supporting tool to strengthen the fixation of the lower jaw. This case reported a 7 year-old-boy who had fracture of his right mandibular corpus. At the time of surgery, it was applied mini plate 5 holes and 4 screws on the right mandibular corpus with the using of circumferential wiring on the right and left mandibular corpus and symphysis, with Gunning splints. The patient was in good condition after surgery without complications. Key words: fracture of the mandible in children, circumferential wiring, Gunning splint
\end{abstract}

\begin{abstract}
ABSTRAK
Fraktur mandibula pada anak-anak biasanya paling banyak terjadi pada kondilus dan angulus. Circumferential wiring dengan Gunning splint merupakan piranti pendukung untuk membantu memperkuat fiksasi rahang bawah. Pada kasus ini, dilaporkan seorang anak laki-laki berusia 7 tahun yang mengalami fraktur corpus mandibula kanan. Pada saat operasi, diaplikasikan mini plate 5 hole dan 4 screw pada corpus mandibula kanan serta penambahan circumferential wiring pada corpus mandibula kanan dan kiri, dan simfisis, dengan Gunning splint. Pasien dilaporkan mengalami perbaikan pasca operasi dan tanpa komplikasi.
\end{abstract}

Kata kunci: fraktur mandibula pada anak, circumferential wiring, Gunning splint

Koresponden: S. Haryoseno, J1. Baros G130, Cimahi, Indonesia. E-mail: senogusi@gmail.com

\section{PENDAHULUAN}

Fraktur mandibula pada anak-anak biasanya terjadi karena sikap tubuh anak yang belum stabil, sehingga mudah terjatuh. Umumnya fraktur terjadi pada awal usia 2-5 tahun karena pada saat itu anak sedang belajar berjalan dan berlari. ${ }^{1}$

Dalam perawatan fraktur mandibula pada anakanak, timbul beberapa masalah yang memerlukan beberapa pertimbangan agar hasil yang dicapai tidak mengecewakan baik bagi operator maupun pasiennya. Masalah perawatan fraktur mandibula pada anak berhubungan dengan pertumbuhan dan perkembangan tulang rahang dan gigi,serta kendala pada perawatan. Makin cepat perawatan dilakukan, makin besar kemungkinan memperoleh prognosis yang baik dan penyembuhan, serta pertumbuhan rahang selanjutnya., ${ }^{2,3}$

Pada artikel ini dilaporkan penanganan kasus fraktur mandibula pada anak akibat mengalami kecelakaan lalu lintas dengan menggunakan teknik circumferential wiring dengan Gunning splint.

\section{KASUS}

Seorang anak laki-laki berumur 7 tahun dirujuk ke Poli Bedah Mulut dan Maksilofasial Rumah Sakit Hasan Sadikin Bandung dari Bagian Bedah Saraf, dengan keluhan rahang bawah patah, karena penderita tertabrak mobil ketika sedang bermain di pinggir jalan tol. Pasien pingsan (+), muntah (-), perdarahan telinga (-), hidung (-), mulut (-).

Pada pemeriksaan ekstra oral terlihat asimetri wajah dengan edema pada bagian bukal sebelah kanan. Dari hasil foto panoramik tampak fraktur corpus mandibula dextra.

Pasien mendapatkan perawatan definitif praoperasi di rumah sakit selama lima hari dan dilakukan pencetakan rahang atas dan bawah.

\section{PENATALAKSANAAN}

Setelah dilakukan anestesi umum, dilanjutkan dengan tindakan aseptik ekstra oral dengan alkohol dan larutan Betadine 10\%, dan intra oral dengan Betadine 10\%, kemudian dilakukan insisi pada daerah submandibula dextra dengan menggunakan pisau no.15. Selanjutnya dilakukan diseksi otot dan tulang pada daerah yang mengalami fraktur dengan menggunakan rasparatorium, kemudian dikuret sampai terlihat garis fraktur. 


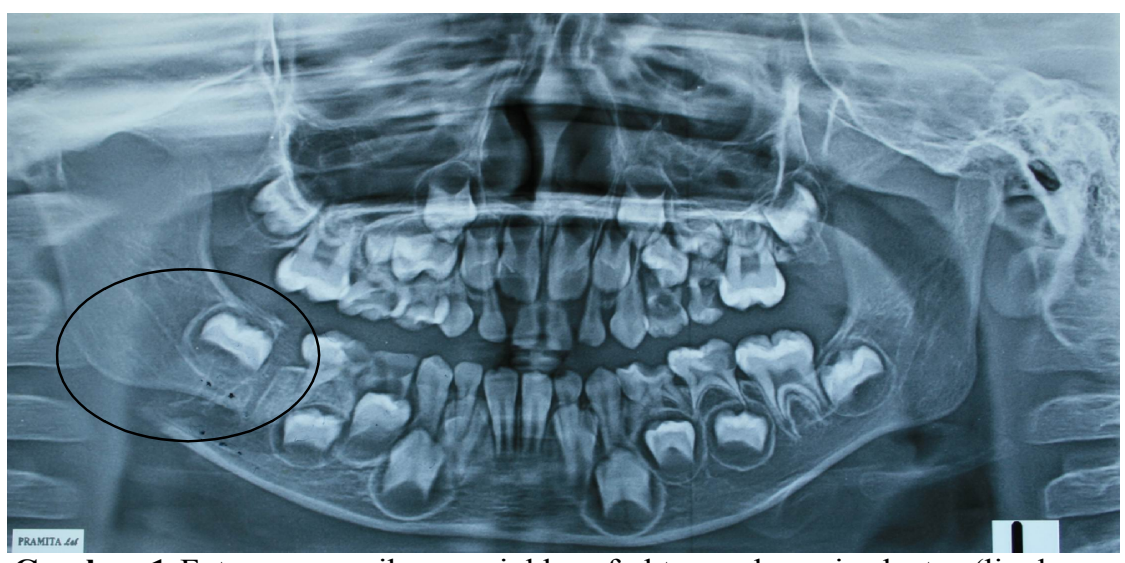

Gambar 1 Foto panoramikmenunjukkan fraktur pada regio dextra (lingkaran hitam).
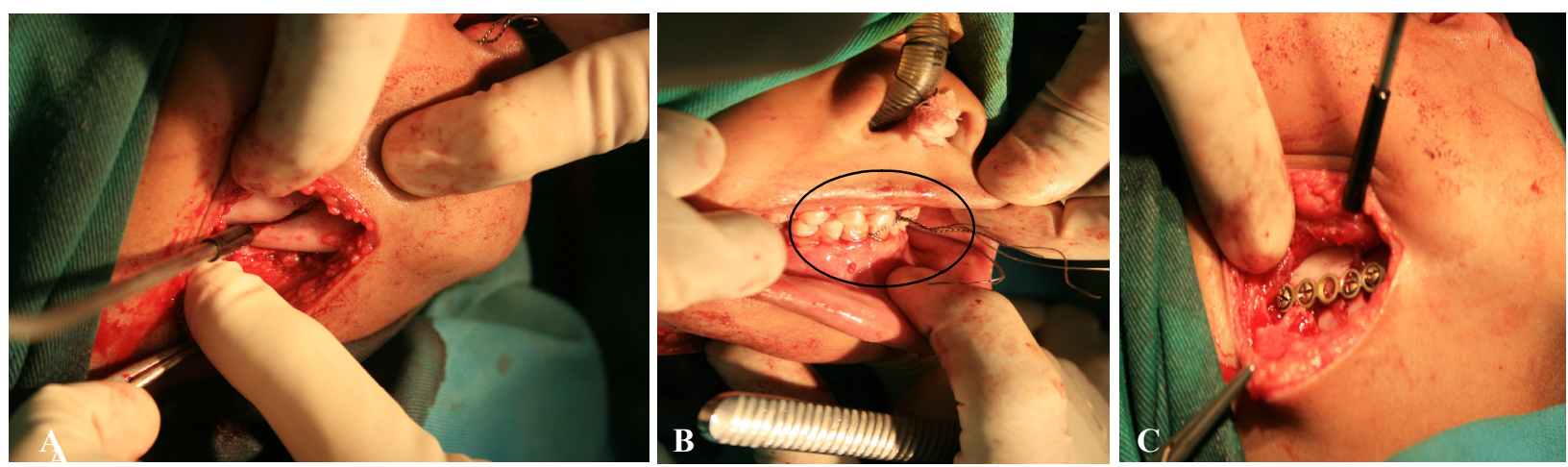

Gambar 2A Insisi submandibula dextra, diseksi otot dan tulang, B Oklusi dengan bantuan fiksasi rahang atas dan bawah, menggunakan metode Ernst, C Pemasangan mini plate 5 hole dan 4 screw
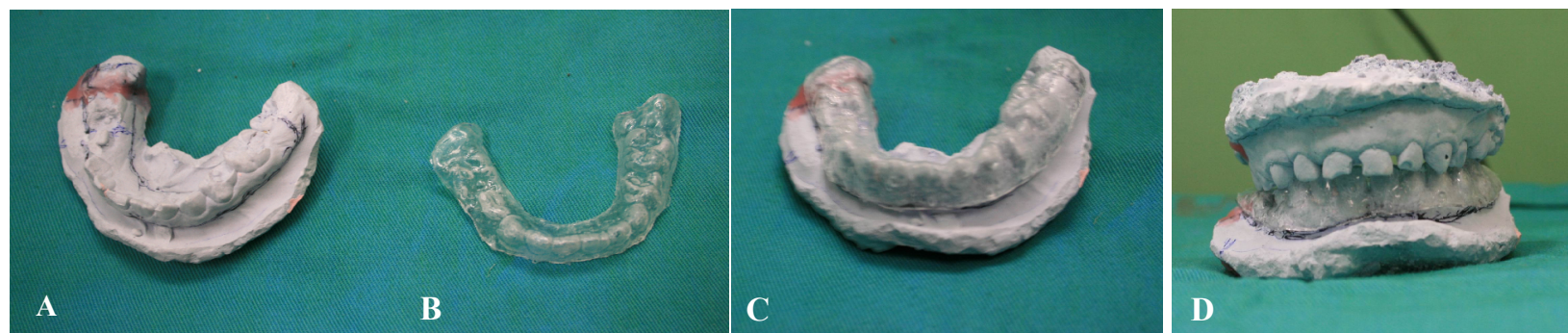

Gambar 3 A Model RB, B Gunning splint, C dan D Gunning splint yang dipasang pada model RB dan RA

Dilakukan reposisi oklusi dan fiksasi gigi geligi rahang atas dan bawah dengan menggunakan metode ernst, kemudian fiksasi garis fraktur dengan bone klem. Selanjutnya, dilakukan penghalusan tulang dengan bone file (gambar 2A dan B).

Selanjutnya dilakukan pemasangan mini plate 5 holes dan 4 screws pada garis fraktur secara horisontal, pada corpus mandibula dextra (gambar 2C).

Gunning splint dipasang (gambar 3), yang ditahan dengan teknik circumferential wiring menggunakan kawat berdiameter ukuran $0,4 \mathrm{~mm}$, dengan menggunakan jarum suntik $10 \mathrm{cc}$ sebagai trocar (gambar 4A dan B) yang diinsersikan dari mucobuccal fold mandibula sinistra menembus bagian submandibula sinistra. Kawat dimasukkan melalui jarum suntik $10 \mathrm{cc}$ sampai keluar ke area submandibula. Selanjutnya jarum suntik $10 \mathrm{cc}$ dilepaskan. Melalui daerah lingual, jarum suntik 10 cc kembali diinsersikan masuk menembus luar submandibula. Ujung kawat yang di ekstra oral dimasukkan melalui jarum 10 cc sampai ke dalam lingual kembali, kemudian jarum tersebut akhirnya dilepaskan. Kemudian kedua ujung kawat difiksasi dengan klamer (gambar 5). Pada titik submandibula ekstra oral dimasukkan kawat dengan ukuran 0.4 $\mathrm{mm}$ kemudian difiksasi dan ditutup dengan self curing acrylic untuk mempermudah pelepasan circumferencial wiring. Tindakan yang sama juga dilakukan pada daerah simphysis dan corpus 

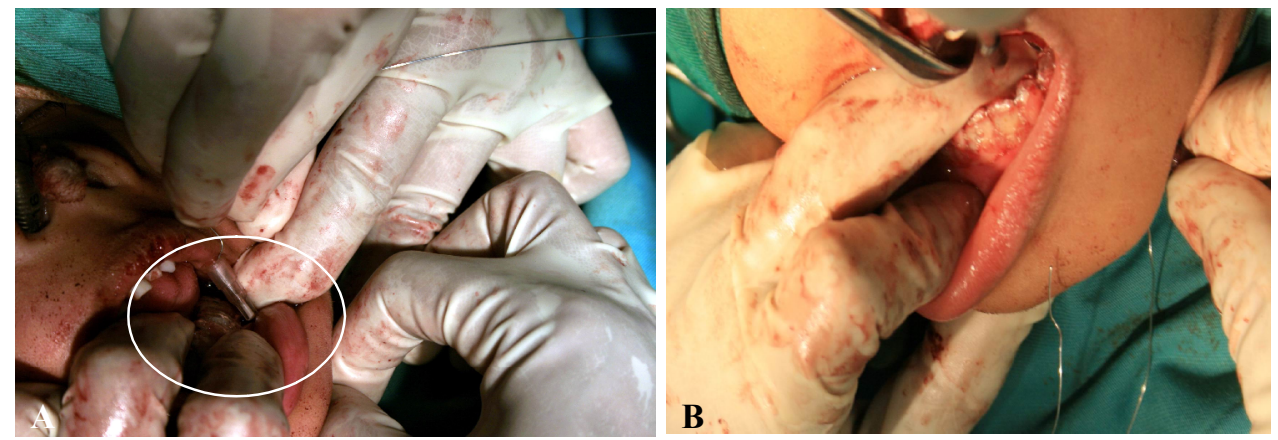

Gambar 4A Kawat 0,4 dimasukkan melalui jarum spuit $10 \mathrm{cc}$ yang diinsersikan dari mucobucofold kiri menembus submandibula, B Kawat 0.4 dimasukkan melalui jarum spuit $10 \mathrm{cc}$ melalui daerah lingual.
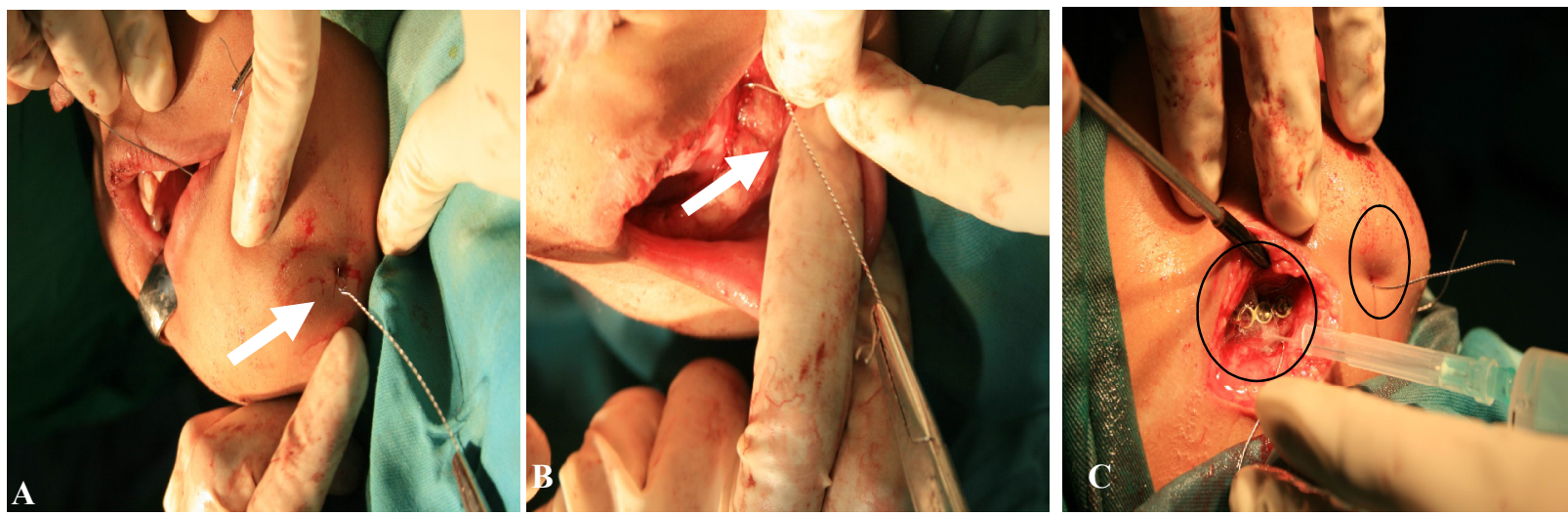

Gambar 5A Fiksasi kawat pada point submandibula, B fiksasi kedua ujung kawat di intra oral. C kawat circumferencial pada submandibula kanan dan kiri, dan pada simphysis

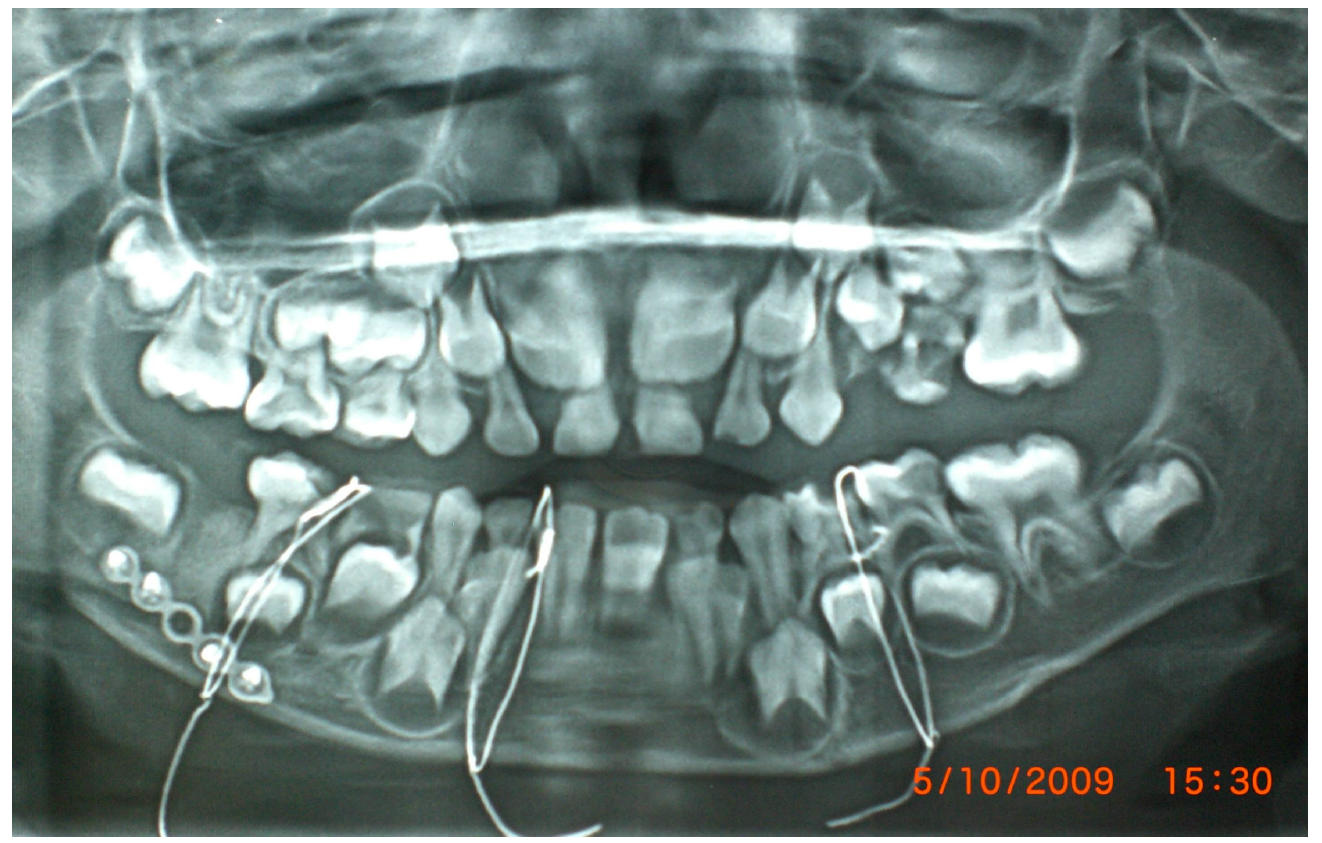

Gambar 6 Foto panoramik post op hari ke 12

mandibula dextra pada garis fraktur yang terjadi (gambar 6). Kondisi pasien menjadi lebih baik pada hari ke-12 (gambar 7A,B,C,D), baik intra maupun ekstra oral.
Pasien kontrol kembali untuk dilakukan pelepasan circumferencial wiring dan Gunning splint pada hari ke-30, yang dilakukan di bawah anestesi umum. 

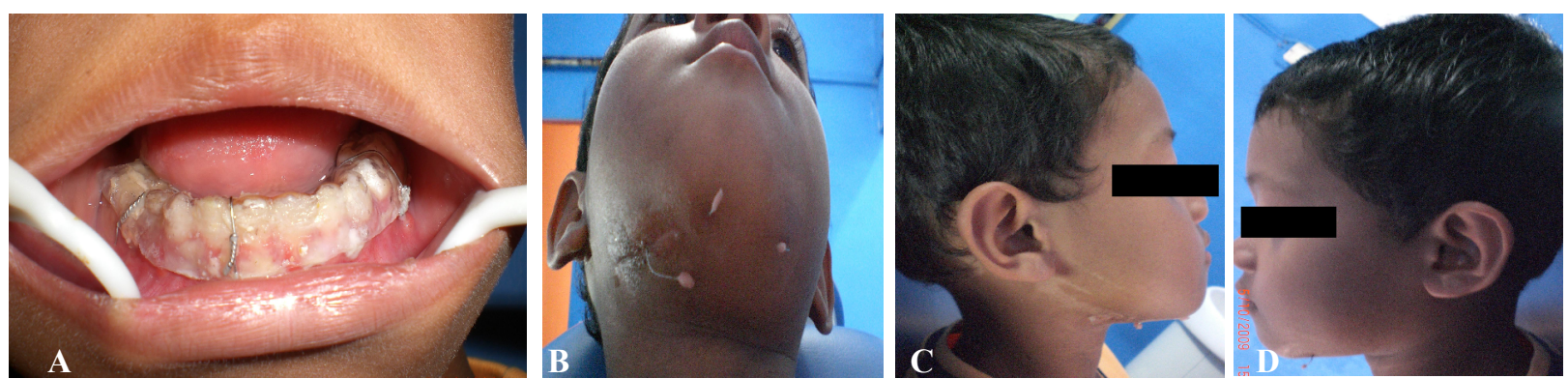

Gambar 7A Foto klinis intra oral post op hari ke 12, B,C,D foto klinis ekstra oral pasca operasi hari ke-12
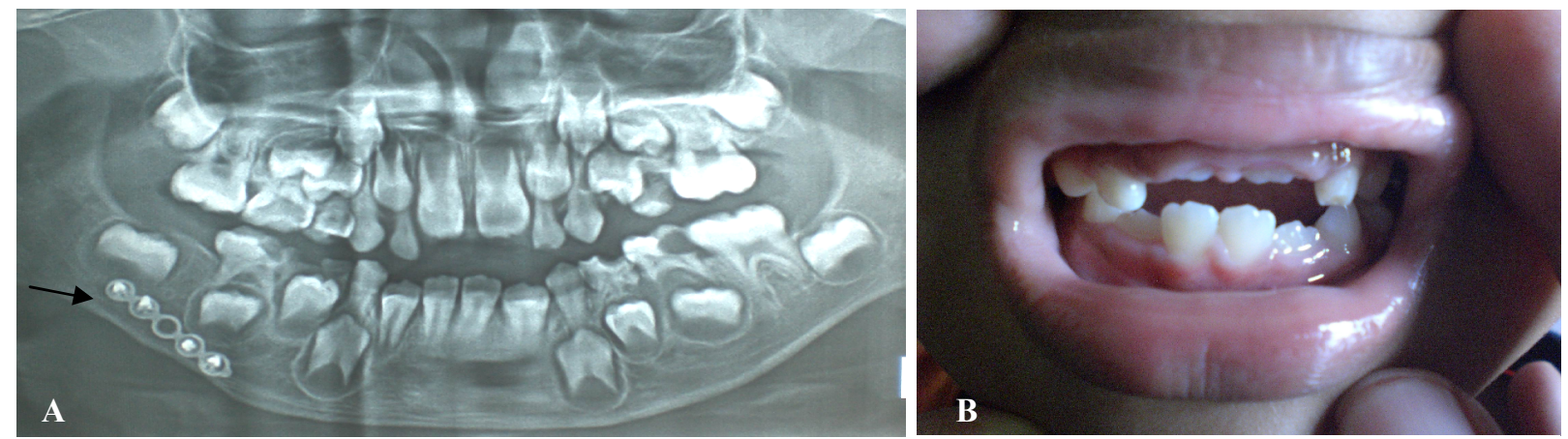

Gambar 8A Foto panoramik pasca pelepasan circumferencial wiring dan Gunning splint bulan ke-6. Tanda panah menunjukkan kalus yang terbentuk pada garis fraktur; B oklusi rahang atas dan bawah bulan ke 6 .

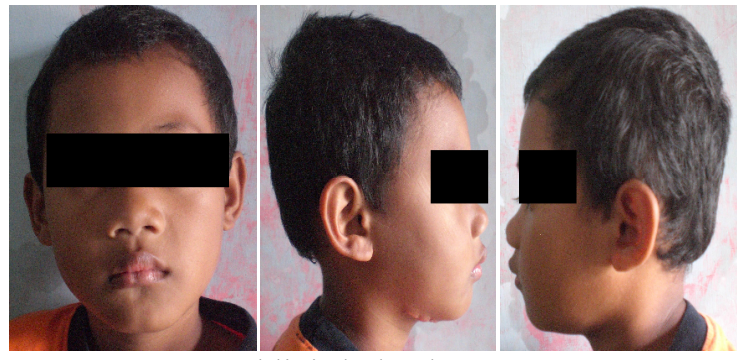

Gambar 9 Foto klinis bulan ke-6.

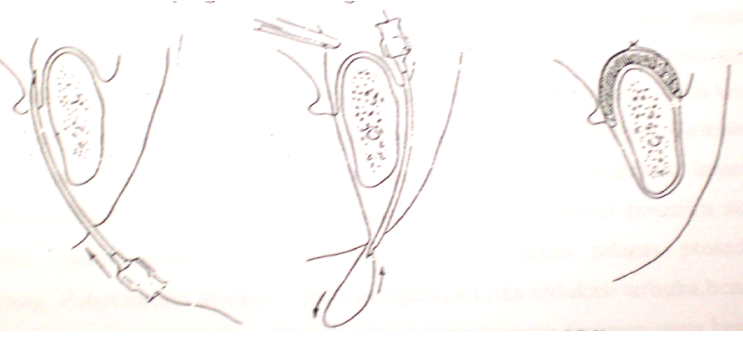

Gambar 16 Circumferential wiring (Sumber: Kruger. Oral and maxillofacial surgery. $6^{\text {th }}$ Ed. Philadelphia: Mosbv: 1984).

\section{PEMBAHASAN}

Fraktur mandibula pada anak biasanya paling banyak terjadi pada kondilus dan angulus. ${ }^{4,5}$ Kaban $\mathrm{dkk}^{3}$ menemukan lebih dari lima puluh persen anak-anak mengalami fraktur mandibula yang melibatkan regio kondilus.

Pada anak-anak dengan gigi permanen yang belum erupsi atau gigi sulung yang tinggal sebagian pada rahang, sebaiknya menggunakan Gunning splint untuk rahang bawah dan ditahan dengan dua kawat circumferential. ${ }^{4}$

Jika reduksi terbuka perlu dilakukan dan tidak dapat dihindari karena pergeseran fragmen yang besar, kawat sebaiknya ditempatkan pada tepi inferior mandibula supaya tidak mengenai benih gigi yang masih tertanam dalam rahang. ${ }^{1}$

Dapat disimpulkan bahwa penatalaksanaan fraktur pada corpus mandibula dextra dilakukan dengan menggunakan mini plate dan screws serta Gunning splint difiksasi dengan circumferential wiring pada corpus mandibula kanan dan kiri, dan pada simfisis. Pada hari ke-30 pasca operasi,terlihat oklusi pasien didapatkan optimal, asimetri wajah yang minimal dan imobilisasi yang lebih baik.

\section{DAFTAR PUSTAKA}

1. Fosenca. Oral and maxillofacial surgery. St Louis: Elsevier Saunders; 2005.

2. Pedlar J. Oral and maxillofacial surgery: an objective-based textbook. $3^{\text {rd }}$ Ed. London: Churchill Livingstone; 2001.

3. Kaban LB. Pediatric oral and maxillofacial surgery. Philadelphia: W.B. Saunders Company; 1990.

4. Kruger. Oral and maxillofacial surgery. $6^{\text {th }}$ Ed. Philadelphia: Mosby; 1984.

5. Peterson. Contemporary oral and maxillofacial surgery. $4^{\text {th }}$ Ed. Philadelphia: Mosby; 2003. 